\title{
Internal inguinal hernia on the transplant side after kidney transplantation: a case report
}

\author{
Akihiro Kondo ${ }^{1}$, Yuji Nishizawa ${ }^{2 *}$, Shintaro Akamoto ${ }^{1}$, Masao Fujiwara ${ }^{1}, K^{2}$ Keiichi Okano ${ }^{1}$ and Yasuyuki Suzuki
}

\begin{abstract}
The patient was a 52-year-old man who presented with right inguinal swelling and pain. He had undergone kidney transplantation in 2005 and bypass surgery using a vascular prosthesis from the left axillary artery to the bilateral femoral arteries in 2008. The vascular prosthesis had invaded the right inguinal canal ventrally. The transplanted ureter had a hazy appearance on a non-enhanced abdominal CT scan. A Lichtenstein operation was performed under a diagnosis of inguinal hernia. A skin incision with pulling of tissue and subcutaneous fat was devised to avoid exposure of the vascular prosthesis. The inguinal canal and spermatic cord were found to have coalesced. The hernia was diagnosed as a supravesical hernia, class II-1. This case shows that a Lichtenstein operation is a suitable procedure for avoidance of damage to the transplanted ureter in treatment of a transplant-side inguinal hernia in a kidney transplant recipient.
\end{abstract}

Keywords: Kidney transplantation; Inguinal hernia; Lichtenstein operation

\section{Background}

The increased frequency of living-donor or brain-dead kidney transplantation has led to observation of rare posttransplant complications, including kidney transplantassociated inguinal hernia. Here, we describe a case in which internal inguinal hernia developed on the transplant side 7 years after living-donor kidney transplantation. We also provide a literature review of this condition.

This literature had been published in Journal of Japan Surgical Association 2014, volume 75(3), 841-844 pages in Japanese [1].

\section{Case presentation}

The patient was a 52-year-old man with a chief complaint of swelling and pain in the right inguinal region, which he had experienced since February 2012. His medical history included a living-donor kidney transplantation in the right iliac fossa for chronic renal failure in 2005. He had also undergone artificial graft bypass surgery from the right axillary artery to the bilateral femoral arteries for treatment of bilateral arteriosclerosis obliterans (ASO) in 2008. He had no particular family medical history.

\footnotetext{
* Correspondence: yunishiz@east.ncc.go.jp

${ }^{2}$ Department of Colorectal Surgery, National Cancer Center Hospital East,

6-5-1, Kashiwanoha, Kashiwa-City, Chiba 277-8577, Japan

Full list of author information is available at the end of the article
}

At the first examination, physical findings were height $179 \mathrm{~cm}$ and body weight $60 \mathrm{~kg}$. Hernia in the right inguinal region was noted in a standing position or while defecation. Blood chemistry findings included urea nitrogen, $40.8 \mathrm{mg} / \mathrm{dl}$; creatinine, 2.44; potassium, $5.4 \mathrm{mmol} / \mathrm{l}$; and hemoglobin, $7.6 \mathrm{~g} / \mathrm{dl}$; all of which indicated renal dysfunction and anemia. On plain abdominal CT, a subcutaneous vascular prosthesis was present on the ventral side of the right inguinal canal (Fig. 1). The transplanted kidney was observed under the right ilium, but the location of the transplanted ureter was unclear (Fig. 2).

Since the position of the transplanted ureter was uncertain, a right ureteral stent was placed before surgery. A skin incision was made at the lower margin of the vascular prosthesis palpable on the caudal side of the right inguinal canal, and the tissue was pulled with subcutaneous fat while avoiding exposure of the vascular prosthesis (Fig. 3). Mild adhesion of the inguinal canal around the spermatic cord was noted. Since a hernia orifice was palpated on the vesical side of the posterior wall of the inguinal canal, the patient was diagnosed with right internal inguinal hernia (supravesical hernia), class II-1 (Fig. 4). After dissecting the hernia sac, radical surgery for hernia was performed using the Lichtenstein method, which a single polypropylene mesh was fixed on the posterior wall of the inguinal canal. The stent

\section{实 Springer}




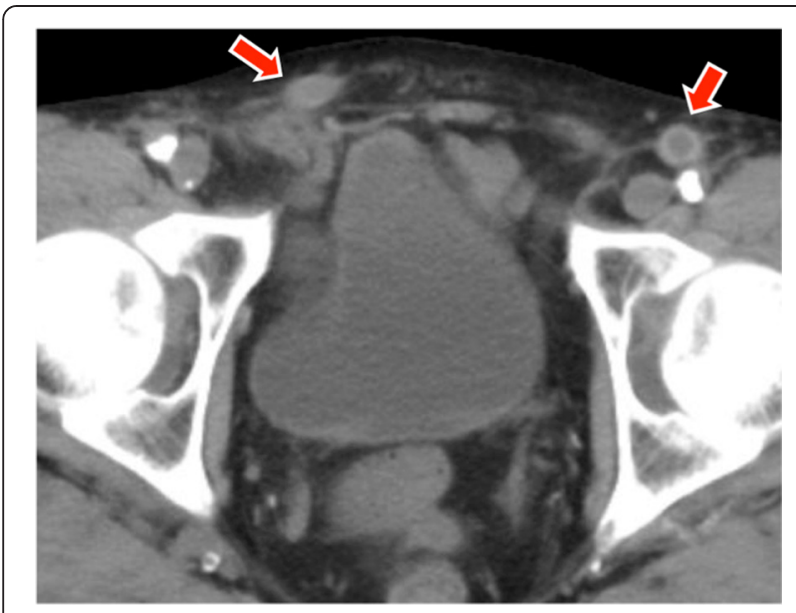

Fig. 1 Non-enhanced abdominal CT scan (axial) showing the vascular prosthesis bilaterally (arrow), one on the right side positioned ventrally in the right inguinal canal

placed in the right ureter was not palpated during surgery. The postoperative course was uneventful, and the patient was discharged 4 days after surgery. No recurrence of hernia or complication has subsequently occurred.

\section{Discussion}

Inguinal hernia is encountered frequently in routine medical practice. The number of kidney transplantations has increased yearly in Japan, with 1610 procedures performed in 2012 alone, based on data from the Japanese Society for Transplantation. However, it is rare to encounter inguinal hernia developing on the transplant side after kidney

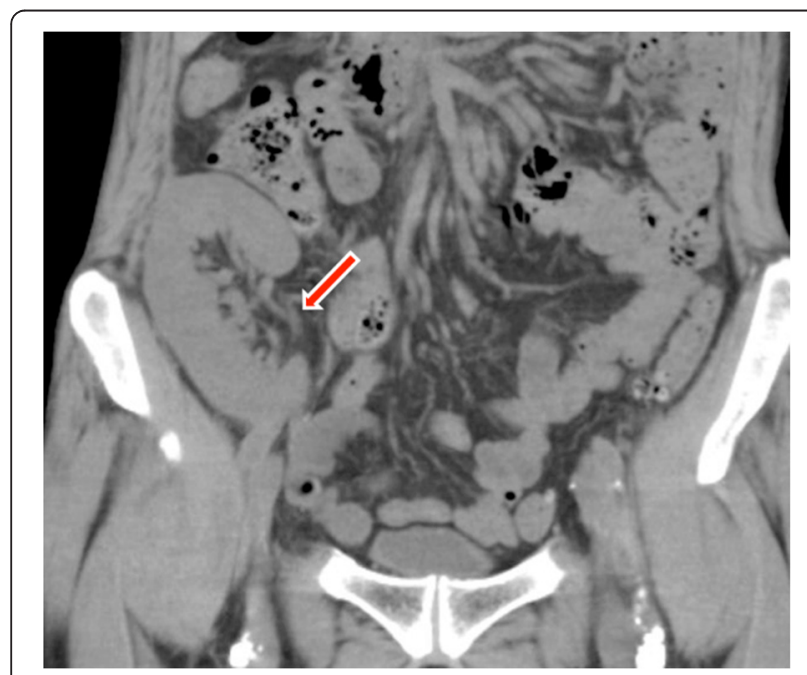

Fig. 2 Non-enhanced abdominal CT scan (coronal) shows that the location of the transplanted ureter is unclear (arrow)

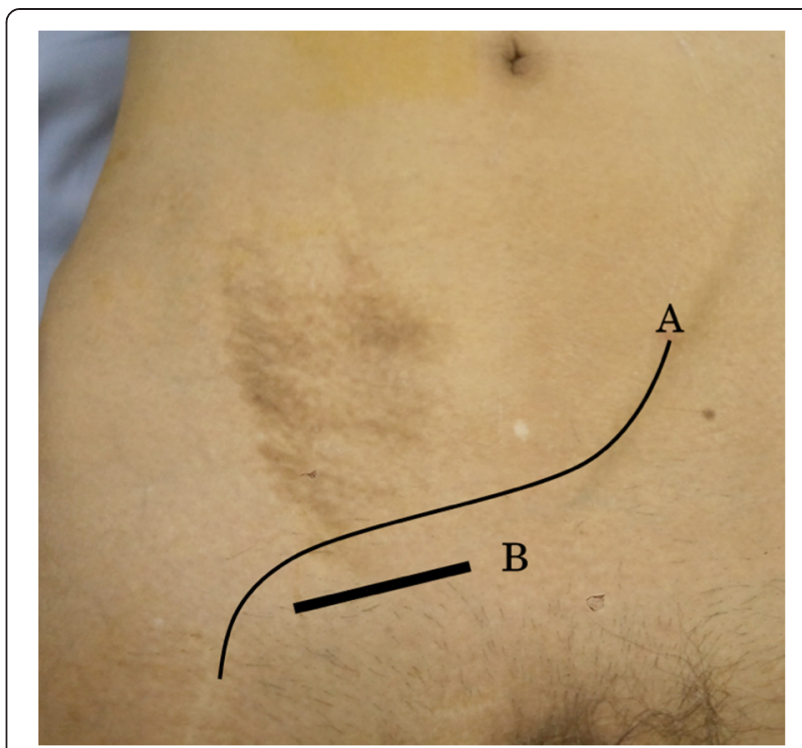

Fig. 3 Preoperative physical findings. A Vascular prosthesis, B skin incision

transplantation, and this condition has to be treated at institutions certified for kidney transplantation.

Hernia occurred on the kidney transplant side in our patient and additionally, a vascular prosthesis had passed through under the skin on the ventral side of the inguinal canal. A skin incision was made on the caudal side in parallel to the vascular prosthesis, and the surgical field was maintained by pulling the tissue with attached subcutaneous fat to avoid exposure of and damage to the vascular prosthesis. Mild adhesion of the inguinal canal around the spermatic cord was noted and may have been due to the surgery performed for kidney transplantation, but dissection was relatively easy. The

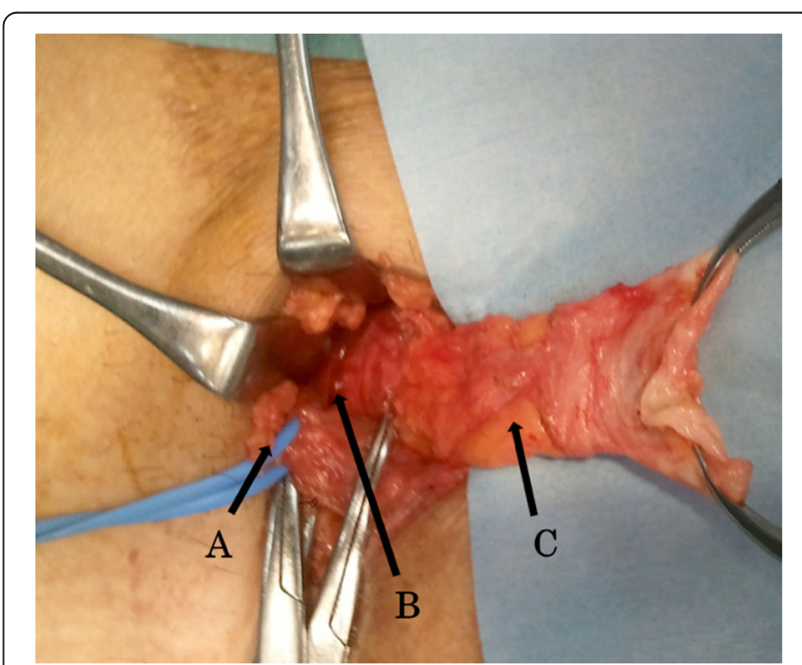

Fig. 4 Intraoperative findings. A Spermatic cord, B hernia orifice, C hernia sac 
transplanted ureter, in which a stent had been placed, was not detected during surgery.

Twelve case reports about inguinal hernia after kidney transplantation has been reported so far in PubMed research (Table 1) [2-13]. Some literatures reported serious intraoperative accidents or postoperative complications in surgery for inguinal hernia associated with kidney transplantation, including unrecognized ligation of transplanted ureter [2], injury to the urinary bladder [3], transplanted ureter necrosis caused by mesh plug $[14,15]$, and transplanted ureteral obstruction caused by transabdominal preperitoneal repair (TAPP) [4]. But then, Koizumi et al. [16] were able to avoid complications involving the transplanted ureter by performing radical surgery for hernia using the Lichtenstein operation.

Lichtenstein et al. [17] first described the Lichtenstein operation for inguinal hernia. In this tension-free surgery, a monofilament polypropylene mesh is inserted into the posterior wall of the inguinal canal. The approaches which insert an underlay mesh into the anterior peritoneal cavity, such as Prolene Hernia System (PHS), direct Kugel methods, and mesh plug methods, may damage a transplanted ureter present in this lesion. In contrast, the Lichtenstein operation does not dissect the anterior peritoneal cavity and, thus, is a most suitable method to prevent complications involving the transplanted organs.

Patients after kidney transplantation take immunosuppressants for a long period, and infectious complications caused by the use of mesh may be a concern. Catena et al. [18] found that the Lichtenstein operation used the porcine small intestine submucosa as a mesh was safe for immunosuppressed patients, but suggested that nonabsorbable polypropylene prostheses is a well-known risk of infection. Since there is a problem of surgical site infection after the mesh repair for the post-transplant patients, it can be considered about optional methods that need no mesh, such as traditional Bassini's or McVay's method and Shouldice repair [19] that is recommended as "tissue repair method".

There have also been 10 case reports (PubMed research) about transplanted ureteral obstruction caused by the inguinal hernia incarceration [5-13], so we need to attend the incidence of inguinal hernia after kidney transplantation. But we were unable to find studies of the relationship between kidney transplantation and the occurrence of inguinal hernia. There has been the need of amassed research evidence of a number of these cases.

\section{Conclusion}

The case reported here illustrates the importance of protection of the transplanted ureter in the treatment of inguinal hernia on the transplant side in a kidney transplant recipient and shows that the Lichtenstein operation is a safe surgical procedure in such cases.

\section{Consent}

Written informed consent was obtained from the patient for publication of this case report and any accompanying images. A copy of the written consent is available for review by the Editor-in-Chief of this journal.

This case report is being approved by the institutional ethical review board of Kagawa University Hospital.

Table 1 Case reports of inguinal hernia after kidney transplantation

\begin{tabular}{|c|c|c|c|c|c|c|}
\hline Author & Year & $\begin{array}{l}\text { Age/ } \\
\text { gender }\end{array}$ & $\begin{array}{l}\text { Post-kidney transplantation } \\
\text { (years) }\end{array}$ & Hernia content & Operation methods & Morbidity \\
\hline Selman [2] & 1985 & $58 / \mathrm{M}$ & 12 & Transplanted ureter & McVay & Ureteric stenosis \\
\hline Kobayashi [3] & 2000 & $39 / \mathrm{M}$ & 4 & N/A & McVay & Urinary bladder injury \\
\hline Sanchez [5] & 2005 & $70 / \mathrm{M}$ & 5 & Transplanted ureter & Lichtenstein & None \\
\hline Furtado [6] & 2006 & $44 / \mathrm{M}$ & 12 & Transplanted ureter & N/A & None \\
\hline Verbeeck [7] & 2007 & $75 / \mathrm{M}$ & 11 & Transplanted ureter & $\mathrm{N} / \mathrm{A}$ & None \\
\hline Ingber [8] & 2007 & $72 / \mathrm{M}$ & 12 & Transplanted ureter & Polypropylene mesh use & None \\
\hline Otani [9] & 2008 & $53 / \mathrm{M}$ & 9 & Transplanted ureter & N/A & None \\
\hline Azhar [10] & 2009 & $76 / \mathrm{M}$ & 20 & Transplanted ureter & N/A & None \\
\hline Odisho [11] & 2010 & $58 / \mathrm{M}$ & 15 & Transplanted ureter & Lichtenstein & None \\
\hline Pourafkari [12] & 2012 & $50 / \mathrm{M}$ & 12 & Transplanted ureter & No operation & Death \\
\hline Tse [4] & 2013 & $57 / \mathrm{M}$ & 3 & N/A & TAPP & Ureteric stenosis \\
\hline Vyas [13] & 2014 & $32 / \mathrm{M}$ & 7 & $\begin{array}{l}\text { Transplanted ureter and } \\
\text { bladder }\end{array}$ & $\mathrm{N} / \mathrm{A}$ & None \\
\hline Our case & & $52 / \mathrm{M}$ & 7 & N/A & Lichtenstein & None \\
\hline
\end{tabular}




\section{Competing interests}

The authors declare that they have no competing interests.

\section{Authors' contributions}

AK and $\mathrm{YN}$ reported the case and wrote the manuscript. YN, SA, MF, KO, and YS made substantial contribution to the conception and design of the study, and they were involved in drafting the manuscript and revising it critically for important intellectual content. All authors declare that they contributed to this article and that they all approve its final submitted version.

\section{Author details}

'Department of Gastroenterological Surgery, Faculty of Medicine, Kagawa University, 1750-1 Ikenobe, Miki-cho, Kita-gun, Kagawa 761-0793, Japan. ${ }^{2}$ Department of Colorectal Surgery, National Cancer Center Hospital East, 6-5-1, Kashiwanoha, Kashiwa-City, Chiba 277-8577, Japan.

Received: 2 February 2015 Accepted: 1 October 2015

Published online: 17 October 2015

\section{References}

1. Kondo A, Nishizawa Y, Akamoto S, Fujiwara M, Okano K, Suzuki Y. Direct inguinal hernia developed on the ipsilateral side of the transplanted kidney -Report of a case-. J Jpn Surg Assoc. 2014;75(3):841-4.

2. Selman SH, Grecos GP, Koo BC. Anuria in a transplant patient following inguinal herniorrhaphy. J Urol. 1985;133(4):669-70.

3. Kobayashi S, Monma T, Adachi W, Nakata S, Yamaura K, Amano J, et al. Urinary bladder injury during inguinal herniorrhaphy in a renal transplant patient: report of a case. Surg Today. 2000;30(1):101-3.

4. Tse GH, Clancy M. Transplant ureteric stenosis complicating laparoscopic recurrent inguinal hernia repair. Hernia. 2013;17(2):271-3.

5. Sanchez AS, Tebar JC, Martin MS, Bachs JM, Moreno MJ, Navarro HP, et al. Obstructive uropathy secondary to ureteral herniation in a pediatric en bloc renal graft. Am J Transplant. 2005;5(8):2074-7.

6. Furtado CD, Sirlin C, Precht A, Casola G. Unusual cause of ureteral obstruction in transplant kidney. Abdom Imaging. 2006;31(3):379-82.

7. Verbeeck N, Niedercorn JB, Mc Intyre D, Pouthier D, Lamy S. Assessment of renal graft obstruction due to ureteral inguinal hernia: US detection and $3 \mathrm{D}$ MR comfirmation. JBR-BTR. 2007;90(2):132-4.

8. Ingber MS, Girdler BJ, Moy JF, Frikker MJ, Hollander JB. Inguinal herniation of a transplant ureter: rare cause of obstructive uropathy. Urology. 2007;70(6):1224.e1-3.

9. Otani LH, Jayanthi SK, Chiarantano RS, Amaral AM, Menezes MR, Cerri GG Sonographic diagnosis of a ureteral inguinal hernia in a renal transplant. J Ultrasound Med. 2008;27(12):1759-65.

10. Azhar R, Boutros M, Hassanain M, Polyhronopoulos G, Chaudhury P, Tshervenkov J, et al. A rare case of obstructive uropathy in renal transplantation: ipsilateral indirect inguinal herniation of a transplant ureter. Transplantation. 2009;88(8):1038-9.

11. Odisho AY, Freise CE, Tomlanovich SJ, Vagefi PA. Inguinal herniation of a transplant ureter. Kidney. 2010;78(1):115.

12. Pourafkari M, Ghofrani M, Riahi M. Inguinal herniation of a transplant kidney ureter: a case report. Iran J Radiol. 2012;10(1):48-50.

13. Vyas S, Chabra N, Singh SK, Khandelwal N. Inguinal herniation of the bladder and ureter: an unusual cause of obstructive uropathy in a transplant kidney. Saudi J Kidney Dis Transpl. 2014;25(1):153-5.

14. Ortiz JA, Palladino H, Thomas S, Zaki R. Mesh plug inguinal herniorrhaphy and ureteral necrosis after kidney transplantation. Transplantation. 2008;86(3):483-4

15. Ortiz JA, Palladino $H$, Thomas S, Zaki R. Mesh plug and ureteral necrosis after kidney transplantation. Hernia. 2008;12(4):433-5.

16. Koizumi M, Sakuma Y, Mori M, Ui T, Sata N, Yasuda Y. Two cases of inguinal hernia on the transplant side after kidney transplantation. J Jpn Surg Assoc. 2010;71(7):1905-8.

17. Lichtenstein IL, Shuiman AG, Amid PK. Use of mesh to prevent recurrence of hernias. Postgrad Med. 1990;87(1):155-8.

18. Catena F, Ansaloni L, Leone A, De Cataldis A, Gagliardi S, Gazzotti F, et al Lichtenstein repair of inguinal hernia with Surgisis inguinal hernia matrix soft-tissue graft in immunodepressed patients. Hernia. 2005;9(1):29-31.

19. Hay JM, Bouder MJ, Fingerhut A, Poucher J, Hennet H, Habib E, et al. Shouldice inguinal hernia repair in the male adult: the gold standard? A multicenter controlled trial in 1578 patients. Ann Surg. 1995;222(6):719-27.

\section{Submit your manuscript to a SpringerOpen ${ }^{\odot}$ journal and benefit from:}

- Convenient online submission

- Rigorous peer review

- Immediate publication on acceptance

- Open access: articles freely available online

- High visibility within the field

- Retaining the copyright to your article

Submit your next manuscript at $>$ springeropen.com 